vesicle is a follicle-a mucous follicle, and lined by mucous membrane. But everything in the anatomy and physiology of the uterus must be made to bend to the cervical despotism which Dr. Bennet would set up.

With reference to some other points, I beg to state that I had commenced obstetric practice, and was using the speculum in the diagnosis and treatment of uterine disease before Dr. Bennet had himself determined what line of practice to follow. When I wrote the paper in 1850 , of which Dr. Bennet complains so much, and in which $I$ questioned the alleged frequency of ulceration, and the propriety of applying the term ulceration to every petty abrasion of the os and cervix, I had not the most remote idea of becoming a candidate for my present ap pointment at St. Mary's Hospital. It was only after the pubfication of the paper in question, that I was invited by some of my present colleagues to come forward as a candidate in opposition to Dr. Bennet. I took no part whatever in the discussions which followed respecting the use of the speculum, except to reply to a paper of Dr. Bennet's, which contained a personal attack upon myself.

Dr. Bennet is at some pains to show that before my election at St. Mary's Hospital, I opposed the use of the speculurn, but that subsequently I resorted to it under circumstances in which I had previously condemned it. Nothing can be more incorrect. In $1850 \mathrm{I}$ did object to the use of the speculum at random in all women presenting themselves at public institutions for treatment. Tables had been published, in which women had been examined by the thousand, not because it was considered necessary in each individual case, bnt to ascertain the per-centage in which uterine disorder existed in women with and without uterine symptoms. Those who followed this plan acted towards living women precisely as Dr. Bennet's supporter, Madoosudun Goopta, very properly acted towards the dead. Against this practice, as regards the living, I wrote, contending that the os uteri and vagina should be treated with a little more reserve than the tongue or the throat, and I have not yet seen reason to regret this. I can truly say that it has never been my practice, with private or public patients, to examine with the speculum except in cases where manifest Eymptoms of local disease exist. Dr. Bennet quotes a passage in my book "On Leucorrhcea," in which I state that, as the rule, I examine "digitally, and with the speculum if necessary," in married persons, "suffering from uterine disease, when the symptoms are severe." Neither more nor less than this do I wish to say, nor have I ever said. Dr. Bennet seeks to draw a contradiction to the above from my writings in 1850 , in which I contend against the use of the speculum in cases where the individual symptoms do not require it. The fallacy of his argument must be obvious to every one. Surely there is some distinction between examining with the speculum in cases of real and severe uterine disorder, and examining them by the thousand, well or ill, in order to frame a statistical table.

Dr. Bennet supposes me to be actuated by the wish to damage his professional character and position. Such imputations are entirely unfounded, and I beg to observe, that in this controversy, Dr. Bennet is himself the aggressor. It was not until he had paraded me for three successive weeks in THE LANCEr, as a convert to his pathological opinions, and as likely hereafter to adopt the plan of treatment, in uterine disease, by deep cauterization, that I felt it due to myself to show that these assertions and vaticinations neither were, nor were likely to become, correct. He says my words are "hard." Facts make words hard. He asks why I do not defend from his attack the views I have advanced in my work on Lencorrhcea? Because I am satisfied to leave the book to take care of itself.

P.S. - Dr. Bennet, in his paper of last week, cites Dr. Scott, formerly of Madras, and now of Ootacamund, as being a very warm supporter of the doctrines advocated by him. I feel bound to say that I have been consulted by a lady, whose uterus was grievously mutilated by Dr. Scott while, with the best intentions, no doubt, carrying out the methods of practice re. commended by Dr. Bennet. In the case I allude to, the posterior uterine lip had been destroyed, and the anterior lip was glued to the rectum. My opinion as to the condition of this lady was first asked, and I was then told her history. The case had led to very great unhappiness, and I had to do my best to calm the husband, who was at the time threatening the personal and other chastisement of Dr. Scott. The husband knew of the state in which his wife was before he came to me for my opinion, and he confirmed it subsequently by other testimony. I should not have dreamt of mentioning Dr. Scott's name, had it not been introduced by Dr. Bennet; but I feel that a great principle is involved, which renders resorve, under the circumstances, impossible.

\author{
ON
}

\section{SYNCOPE SENILIS, ARISING FROM GASTRIC IRRITATION.}

\section{Bx JOHN HIGGINBOTTOM, Esq., F.R.S., F.R.C.S., \&c.}

I HAVE given the name of "syncope senilis" to this affection, particularly to direct the attention of the profession to the aged. The same complaint is common to all ages, but in a more aggravated form in infancy and old age. I am not aware that the affection has been specially noticed by any author, except under the head of indigestion, and the sufferers themselves often call it a bilious attack. I do not think that the symptom of syncope is so apparent in infancy; and I believe in middle age the attacks are slighter, and not often serious. The syncope in old age is very apparent, and is the first symptom requiring prompt attention, for if remedies are neglected, the complaint becomes sometimes much aggravated, and is followed by convulsion and death.

It is about thirty years since I first noticed particularly the syncope senilis. The subject was about seventy years of age. I thought at that time it was a precursor of an attack of apoplexy, the patient having had a slight paralysis when about twenty-three years of age, which affected him slightly throngh life. I was glad to find, on his recovery, that there was no increase of his paralytic symptoms. Since that time, I have often observed the same syncope, unattended by any permanent ill effects.

My patients have been from sixty-eight to eighty-six years of age; the youngest sixty-eight, the oldest eighty-six. I am not aware that they have laboured under any organic disease whatever; but we all know, that at an advanced age the brain and heart, the nervous and vascular system, are frequently more inactive, and in an impaired condition.

In the cases I have attended of syncope senilis, gastric irritation appears to have been the sole cause of the attack. At that advanced age, mastication of the food is very imperfectly or not at all performed, for want of teeth; solid animal food. has been eaten when the stomach has been in an unfit state to assimilate it, usually after having had a longer walk than the patient has been accustomed to, or had more muscular exertion than usual, so as to produce fatigue, and sometimes after exposure to cold; all which tend to weaken the power of the stomach. On this account the food remains an indigestible mass in the stomach, and gives rise to gastric irritation, producing syncope and convulsion, which sometimes follows, often slight at first, but becoming more formidable, or even fatal, if proper remedies are not promptly used.

I was called to a patient about three o'clock in the morning, his wife having been awoke by his hard breathing and noise in his throat. She found her husband was in a fit. I was directly sent for. When I arrived he had partially recovered, but very soon after he had a second fit, which had the appearance of a slight attack of epilepsy, attended with convulsion, but had no bitten tongue, as is usual in severe attacks of epilepsy. As soon as he was sufficiently recovered from the attack, so that he could swallow, I gave him half a drachm of the powder of ipecacuanha with fifteen grains of the bicarbonate of potass, which was followed by full vomiting; he ejected lumps of solid beef, which appeared to have been swallowed, or rather bolted, without having been masticated at all; one of the pieces, $I$ observed, was about an inch long and three quarters of an inch in thickness. Although the food had been taken into the stomach about sixteen hours, the acute corners and edges of the beef appeared as if just cut with a sharp knife, not the least digested. No further remedy was required after the emetic, but attention to the bowels, which he reluctantly submitted to, saying he was quite well.

In a month afterwards he had another fit of a similar nature. He fell down in a moment on the floor, and remained in the same state as in the former case for half an hour; the same remedies were resorted to as before, and he recovered quickly. I expect the patient will have a return of the syncope, as he is very wilful, and will not attend to any means of prevention. This patient was the youngest, being sixty-eight yearrs of age. Previous to the first fit he had been using much muscular exertion, still being active in business.

Another case is that of an old patient of eighty-six years, who at intervals of a few weeks had several similar attacks of syncope. After the last fit, attended with slight convulsion, I was in453 
duced to think it had been occasioned by taking solid food, which was swallowed afterimperfect mastication; on that account I forbade him the use of animal food altogether. This regimen he has now strictly adhered to for some months, except a few times having taken a small quantity of tripe. He has had no return of his fainting fit, a much longer time having now elapsed than the interval, after which he had several of the previous attacks. I would make an observation here, as a contrast to the former case I have related in the younger man, that at a more advanced age the patient does not recover so quickly from the attack, but requires particular attention to the digestive organs for some days, with gentle aperients, and saline medicine in a state of effervescence.

It is not unusual for even young men to have similar attacks from indigestion, when sudden syncope for a short period comes on, recovery taking place in a few moments. The same attack at an advanced age, I presume, would be attended with aggravated symptoms, such as those I have witnessed.

The lamentable illness and death of the Duke of Wellington appears to me to have been a case of "syncope senilis," which became aggravated, and terminated fatally. In the "Life of the Duke of Wellington," by Stocqueler, it is stated that " the health of his Grace had been unusually good for some days, and on Monday, the 13th of September, it was remarked that he took a longer walk than usual through the grounds attached to the Castle." THE LANCEx of the 16th October, 1852, in the leading article, says, "During some days preceding the 14th September, 1852, the day of the Duke's death, there had been a hot midday sun, a considerable wind, chiefly from the north, and the evenings and nights were cold and chilly. The thermometer, on the night preceding the fatal event, was only six degrees above the freezing point; on the preceding day it had been up to ninety-two degrees Fahr. No precautions were taken to obviate the effect of such a change on the aged and necessarily weak system of the Duke, and the pallor of his countenance observed on the preceding Sunday showed that this influence was telling on the circulation. The stomach was ill prepared to receive a hearty dinner, and the difficulties of that organ were further increased by receiving a considerable quantity of food imperfectly masticated in consequence of the Duke's loss of teeth." ...... "He took for dinner, mock turtle, turbot, venison, and pudding." It is further added in Tre LANCET, " It is probable that had the Duke's stomach been relieved by vomiting in the early part of the morning, he would now be with us ; it is even probable that such an effort, if successful at nine o'clock, might have saved him; but every hour added to the exhaustion, and rendered such an act difficult."

My brother-in-law, Dr. Marshall Hall, observes, in a paper in The Lancet of October 30th, 1852, "On the Malady of the late Duke of Wellington," - "It is obvious that if efficient vomiting could have been induced, the offending cause of this lamentable malady would have been removed, and all might have been well; he would, humanly speaking, still be with us. We have no evidence that the Duke of Wellington had any organic disease of either the brain or the heart. It is to be re gretted that there was no post-mortem examination."

$I$ fully concur with the leading article in THE LANCET, and with Dr. Marshall Hall's opinion, that an efficient vomiting at an early period would have been a most effectual remedy.

I know no emetic equal in such a case to half a drachm of the powder of ipecacuanha, with the addition of ten or fifteen grains of the bicarbonate of potass, as it corrects any acidity in the stomach, and produces full vomiting both safely and quickly; it has also the power of raising the system to its normal condition, without producing any unnatural excitement, and promotes the healthy secretions of the various organs of the body. The nausea and inefficient vomiting arising from natural efforts to empty the stomach, I have no doubt produces debility and exhaustion, when a full vomiting from ipecacuanha has the contrary effect. Should the first half-drachm of ipecacuanha not operate, a second such dose may be given with the greatest safety, it only having the effect of a more speedy operation. If vomiting still should not follow, the fauces might be irritated with a feather, to excite it. I have for the last forty years given ipecacuanha emetics with the same freedom as I have purgatives, and never saw any bad result.

It might be thought by some individuals that abstaining from animal food at the period of old age might be attended with the loss of health and strength. I had an instance in a relation of my own family, who, at seventy years of age, quite abstained from animal food, and also from wine. After the lapse of ten years, when at the age of eighty, he was requested by his relatives to resume his animal food and wine, he excused himself from taking either of them by saying he did not want them, for he was very healthy, and in good spirits, although very thin in body. He lived till he was nearly ninety years of age. This old gentleman, I apprehend, would have been a likely subject for the symcope senilis had he been in the habit of taking solid animal food, which he could not masticate, and would most probably have shortened his days.

At an advanced age, when the physical powers of the body are declining, and second childhood approaching, and at that period when comparatively little exercise only can be taken, the body does not require the same solid food. Nature points out the use of milk and light farinaceous matter as an aliment, as being more natural, and adapted to that period of life; such food alone is sufficient to keep the body in a healthy, cheerful, and happy state. It has been erroneously stated that "wine is the milk of old age;" I believe the truth is, that milk is the wine of old age, for both the first and second childhood, the most natural and the most nutritious. Dr. Erasmus Darwin used to say, "Milk is white blood." "The oldest individuals 1 have known, have lived principally upon milk diet. Second childhood may be treated much in the way as directed by the late Dr. James Hamilton, professor of midwifery in the University of Edinburgh: "Plenty of milk, plenty of flannel, and plenty of sleep or rest."

Nottingham, 1856.

\section{ATTEMPT AT STRANGULATION, PRO- DUCING EPILEPSY; RECOVERY.}

\section{By AMOS BEARDSLEY, Esq., M.R.C.S.E., Tlverstone.}

Mrs. M- , wife of a sweep, a woman of degraded moral character, with several marks of a syphilitic nature upon her person, but not subject to intoxication, about six months advanced in her seventh pregnancy, after some altercation with her husband, to whom she had only returned a few days before, having been absent from her home for a month previously, attempted, on Feb. 4th, I856, to destroy herself by strangulation. In the morning of the same day she had once or twice attempted to throttle herself, but was prevented by her husband. During his absence in the afternoon, about three o'clock, she had proceeded upstairs, followed by a neighbouring woman, when she requested her to go and fetch her a little water to drink. She did so, and upon returning found her kneeling down by the bedside, with her head leaning upon the bed, and quite black in the face. She immediately gave an alarm, and; upon examining her, they found she had tied her handkerchief round her throat as tight as possible, making three knots in it; and, to make it tighter, had thrust her thumbs in under the ligature, just over the pomum Adami. The handkerchief was immediately loosened, but the woman was quite unconscious, and appeared completely lifeless. She was placed upon the bed, and medical assistance sent for. Upon reaching her, I found her lying upon the bed, just as they had placed her, and just recovering from a violent epileptic convulsion. This was in a few moments followed by another. Upon inquiry, I found the convulsions set in immediately the handkerchief was loosened and she was put upon the bed. There was a red mark all round the neck where the ligature had been applied, more particularly on the back and sides of the neck, owing to the thumbs being thrust in between at front. The pulse was feeble, and the respiration rather embarrassed; the lividity of the face was giving place rather to pallor. The tongue was not at all protruded, neither was it bitten during the epileptio seizures, but the maxilla were very forcibly driven together, and there was great distortion of the mouth, eyes, and face. There was also foaming at the mouth, but I did not observe it to be at all bloody. The urine was evacuated involuntarily, so that her female attendants thought the membranes must have given way, and the "waters" have escaped. She had pains in her back and bowels, the whole of the following day, to such an extent that they expected a mis. carriage or premature birth, and had a midwife in attendance; but a few doses of an anodyne quieted them, and they passed off altogether. As the convulsions did not seem disposed to cease at all, I ordered an enema of oil of turpentine (half a drachm), with half a drachm of sulphuric ether to be administered at once in a little tepid gruel. This had the desired effect of at once checking the convulsions.

I ought to state, that when I first saw her $I$ observed the museles of the neck to be firmly contracted, the sterno-mastoid and platysma in particular; but the whole of the muscles of the neck seemed very rigid-genio-hyoid, omo-hyoid, \&c. After the enema had been administered, these were all observed 